\title{
Biopolymer Augmentation of the Lag Screw in the Treatment of Femoral Neck Fractures - A Biomechanical in-Vitro Study
}

\author{
A. Paech, E. Wilde, A. P. Schulz, G. Heinrichs, R. Wendlandt, C. Queitsch, B. Kienast, Ch. Jürgens \\ Klinik für Chirurgie des Stütz- und Bewegungsapparates, Universitätsklinikum Schleswig-Holstein, Campus Lübeck, Germany
}

\begin{abstract}
The cut-out of the sliding screw is one of the most common complications in the treatment of intertrochanteric fractures. The reasons for the cut-out are: a suboptimal position of the hip-screw in the femoral head, the type of fracture and poor bone quality. The aim of this study was to reproduce the cut-out event biomechanically and to evaluate the possible prevention of this event by the use of a biopolymer augmentation of the hip screw.
\end{abstract}

Concerning the density and compression force of osteoporotic femoral bone polyurethane foam according to the terms of the Association for Standard Testing Material (ASTMF 1839-97) was used as test material. The polyurethane foam Lumoltan 200 with a compression force of $3.3 \mathrm{Mpa}$ and a density of 0.192 $\mathrm{g} / \mathrm{cm}^{3}$ was used to reproduce the osteoporotic bone of the femoral fragment (density $12 \mathrm{lbm} / \mathrm{ft}^{3}$ ). A cylinder of $50 \mathrm{~mm}$ of length and $50 \mathrm{~mm}$ of width was produced by a rotary splint raising procedure with planar contact.

The axial load of the system was performed by a hydraulic force cylinder of a universal test machine type Zwick 1455, Ulm, Germany. The CCD-angle of the used TGN-System was preset at 130 degrees.

The migration pattern of the hip screw in the polyurethane foam was measured and expressed as a curve of the distance in millimeter $[\mathrm{mm}]$ against the applied load in Newton $[\mathrm{N}]$ up to the cut-out point. During the tests the implants reached a critical changing point from stable to unstable with an increased load progression of steps of 50 Newton. This unstable point was characterized by an increased migration speed in millimeters and higher descending gradient in the migration curve. This peak of the migration curve served as an indicator for the change of the hip screw position in the simulated bone material. The applied load in the non-augmented implant showed that in this group for a density degree of $12\left(0,192 \mathrm{~g} / \mathrm{cm}^{3}\right)$ the mean force at the failure point was 1431 Newton $( \pm$ 52 Newton). In the augmented implant we found that the mean force at the failure point was 1987 Newton ( \pm 84 Newton). This difference was statistically significant.

In conclusion, the bone density is a significant factor for the stability of the hip screw implant. The osteosynthesis with screws in material with low density increases the chance for cut-out. A biopolymer augmented hip screw could significantly improve the sta- bility of the fixation. The use of augmentation with a fast hardening bone replacement material containing polymer-ceramic changes the point of failure under axial load in the osteoporotic bone model and could significantly improve the failure point. Our study results indicate, that a decrease of failure in terms of cut-out can be achieved with polymer augmentation of hip screws in osteoporotic bones.

\section{INTRODUCTION}

Proximal femoral fractures in the elderly are often related to minor falls and osteoporosis [18]. The operative stabilization by nails or plates with a stabilizing screw in the femoral neck is the gold standard in medical treatment at the current time.

The cut-out of this screw is one of the most common complications [1, 16, 51, 59]. Revision is usually related to high rates of complications (wound infections, bleeding, need of transfusion, pulmonary infections, pulmonary embolism, deep venous thrombosis, etc.).

The reasons for the cut-out are the suboptimal position of the hip-screw in the femoral head [5], the type of fracture (especially a calcar defect) and also poor bone quality. This does not allow the implant to have enough hold. Severe osteoporosis is often found in patients who are more than 80 years old [1, 16, 45]. Numerous biomechanical studies analyzed the failure of individual implants in cadaveric tests $[13,25,26$, $29,35,63]$. These studies have to be analyzed critically. In these studies different techniques were used and they were performed in bone models with incomparable grades of osteoporosis. Because of the different bone strength and different techniques the studies lack reproducibility.

The aim of this study was to reproduce the cut-out event biomechanically and to perform a statistical analysis to evaluate the possible reduction of this event by the use of a biopolymer augmentation of the hip screw. A specific device was developed and it was used in an artificial bone model.

\section{Materials And Methods}

The bone structure and density in the proximal part of the human femur is variable and therefore extremely individual. That is why we used an artificial osteoporosis model in our study instead of human cadaver mate- 


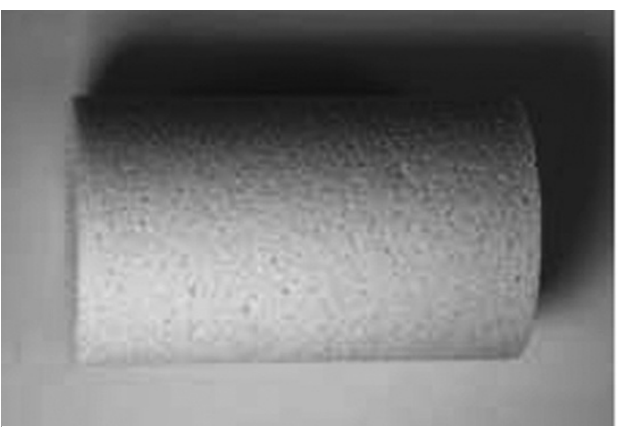

Fig. 1. Polyurethanic foam cylinder $50 \mathrm{~mm} \times 30 \mathrm{~mm}$.

rial to fulfill the principle of reproducibility in the tests.

Concerning the density and compression force of osteoporotic femoral bone polyurethane foam according to the terms of the Association for Standard Testing Material (ASTMF 1839-97) was used as bone material. The polyurethane foam Lumoltan 200 (Lackfa Isolierstoff $\mathrm{GmbH}$, Rellingen, Germany) with a compression force of $3.3 \mathrm{Mpa}$ and a density of 0.192 $\mathrm{g} / \mathrm{cm}^{3}$ was used to reproduce the osteoporotic bone of the femoral fragment (density $12 \mathrm{lbm} / \mathrm{ft} 3$ ). A cylinder of $50 \mathrm{~mm}$ of length and $50 \mathrm{~mm}$ of width was produced by a rotary splint raising procedure with planar contact area (Fig. 1).

For the biomechanical testing of the migration characteristics of biopolymeric augmented and non-augmented hip screws, the Gamma-Nail System (Fig. 2, TGN, STRYKER, Schönkirchen, Germany) was used.

The gamma nail consists of a hip screw with a 12.0 $\mathrm{mm}$ thread diameter (Fig. 3) and an intramedullary nail as force carrier. After axial intramedullary drilling, the introduction of the cannulated nail is followed by the application of the hip screw in the proximal fragment. This is guided by an aiming device. By pre-drilling using a graduated drill the self-cutting hip screw can be applied correctly. At the distal end of the nail a locking screw is inserted to stop the rotation of the hip screw.
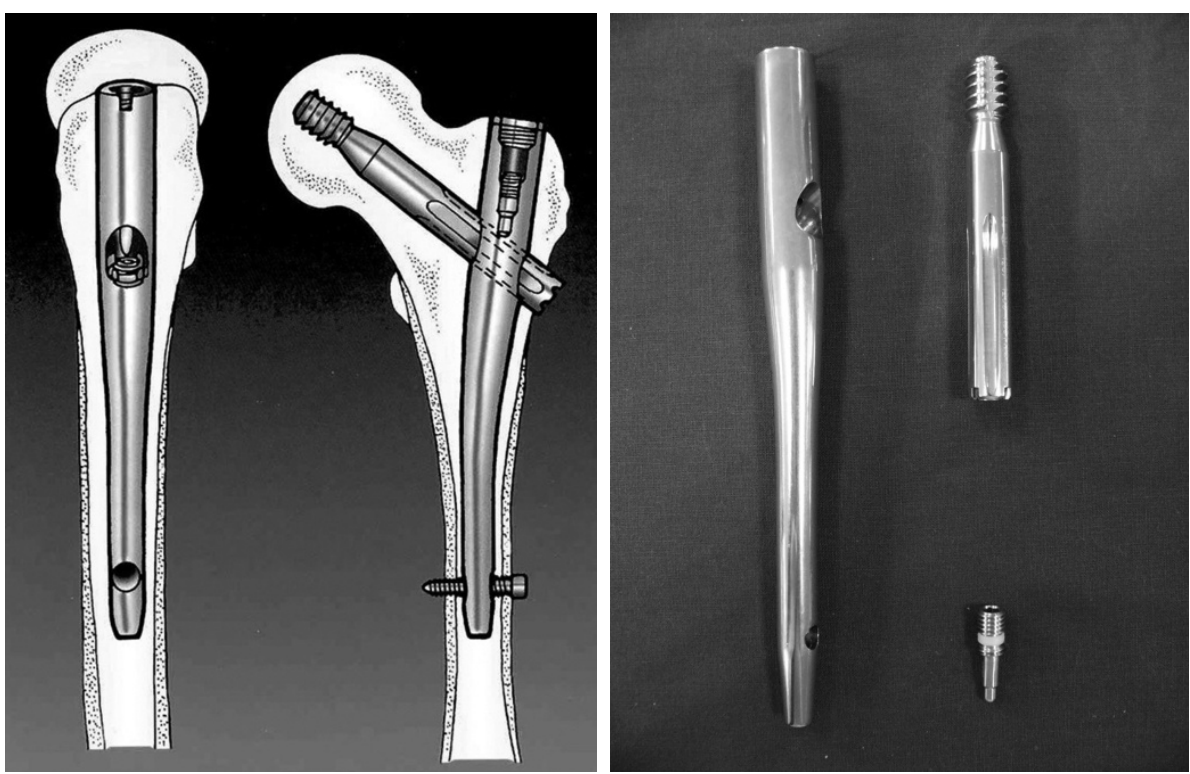

Fig. 2. Left: Position of the TGN in the proximal femur; Right: $130^{\circ}$ TGN, hip screw. 


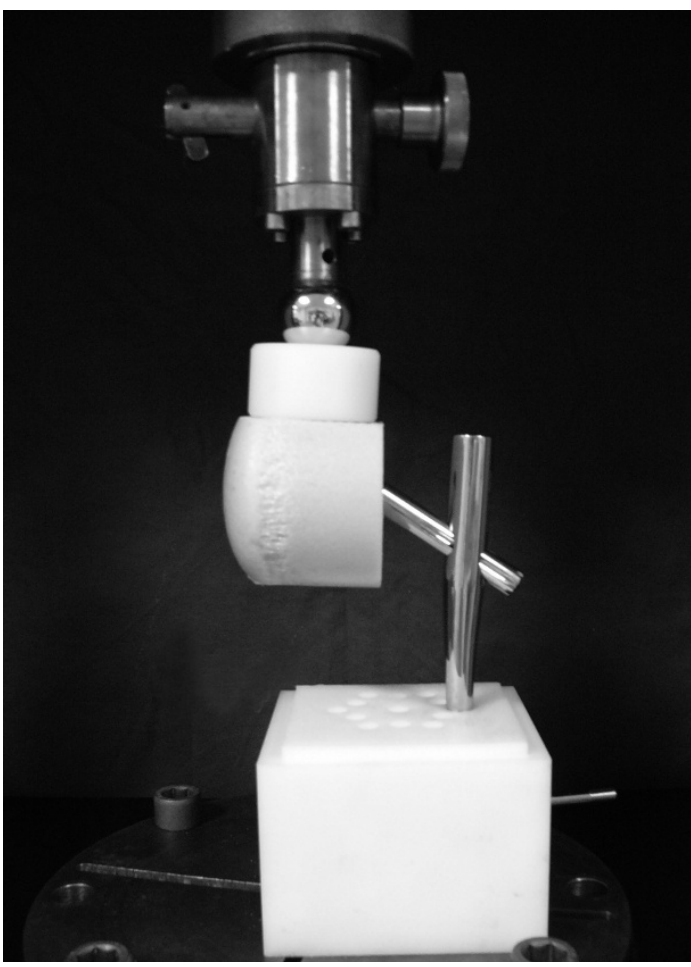

Fig. 4. Test arrangement mounted on MTS Zwick 1455.

curve (point-of-change) with plastic deformation (Diagram 1 and 2). The preparation of the polyurethane cylinders was performed using the original instruments with a standardized technique following the operation manual. The procedure was performed by an experienced orthopedic surgeon. The pre-drilling of a standardized channel using the corresponding drill top was possible by using the automatic guide of a box column drill (Fig. 5). The drill had constant speed rotation and manual heading. With the TGN graded-drill a 38 millimeter deep channel was performed and afterwards the hip screw was manually inserted up to the designated depth of 36 millimeter.

For the second part of the test the same procedure was followed with the additional application of $2 \mathrm{ml}$ of the biopolymer „Corthoss“ (polymer with glass-ceramics particles, Corthoss, Orthovita, Malvern, USA) in the screw channel (Fig. 6). The influence of biopolymer augmentation of the hip screw was simulated to analyze the stability of the implant and to find any changes in the cut-out point.

The applied biopolymer hardened within 4 minutes after application on the hip screw and was afterwards tested biomechanically. All the test series consisted of 5 tests. All the results were analyzed and compared statistically. Statistical evaluation was performed with SPSS (version 16.0, SPSS Inc., Chicago, USA).

\section{RESULTS}

The migration pattern of the hip screw in the polyurethane foam was measured and expressed as a curve of the distance in millimeter [mm] against the applied load in Newton $[\mathrm{N}]$ up to the cut-out point. During the tests the implants reached a critical chang-

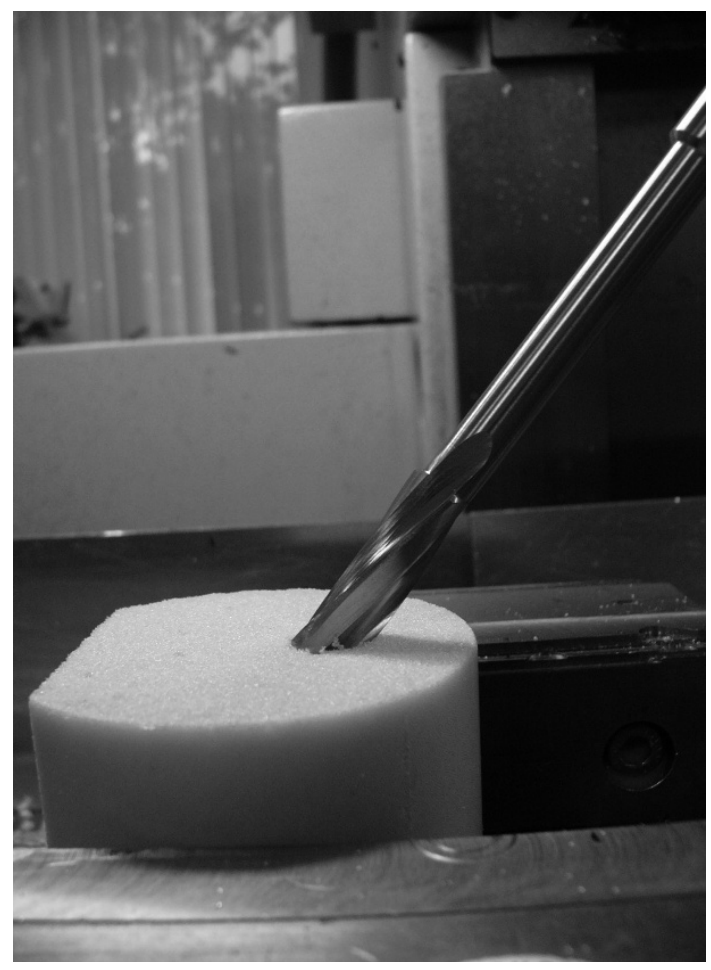

Fig. 5. Three-graded drill (TGN and Gamma 3).

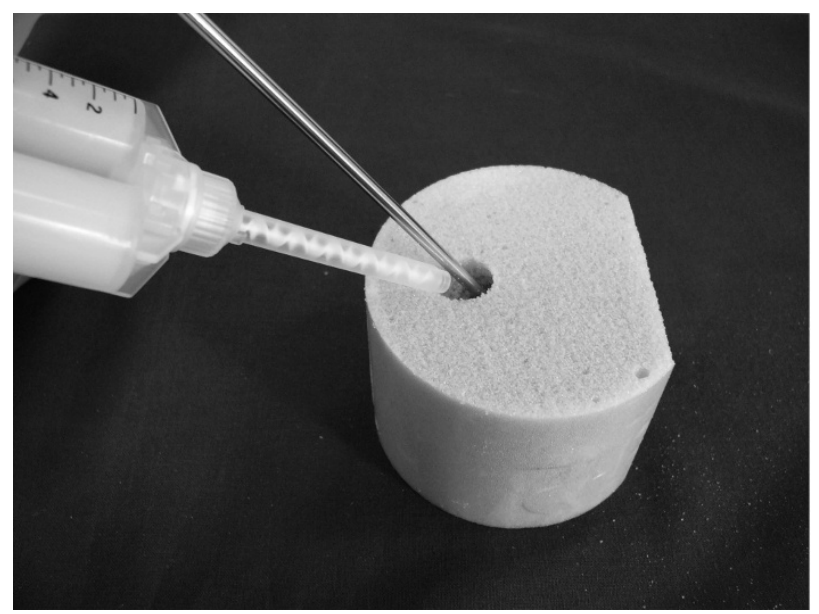

Fig. 6. Polyurethane foam cylinder with application of biopolymer (Corthoss).

ing point from stable to unstable with an increased load progression of steps of 50 Newton. This unstable point was characterized by an increased migration speed in millimeters and higher descending gradient in the migration curve. This peak of the migration curve served as an indicator for the change of the hip screw position in the simulated bone material.

The applied load in the non-augmented implant showed that in this group for a density degree of 12 $\left(0.192 \mathrm{~g} / \mathrm{cm}^{3}\right)$ the mean force at the failure point was 1431 Newton ( \pm 52Newton). In the augmented implant we found that the mean force at the failure point was 1987 Newton ( \pm 84 Newton). This difference was statistically significant (using a Two-Tailed Student-TTest) with $\mathrm{p}=0.032$. 


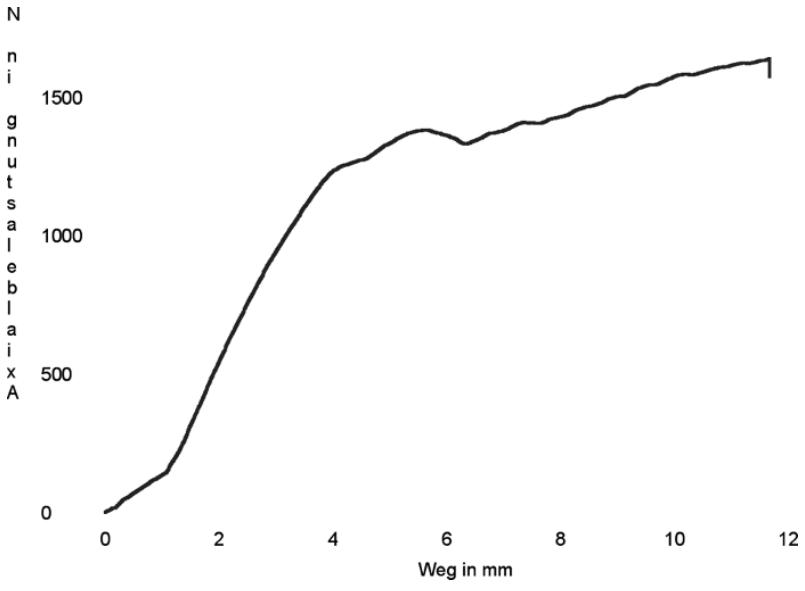

Diagram 1. curve without augmentation F max.: 1645.99 N.

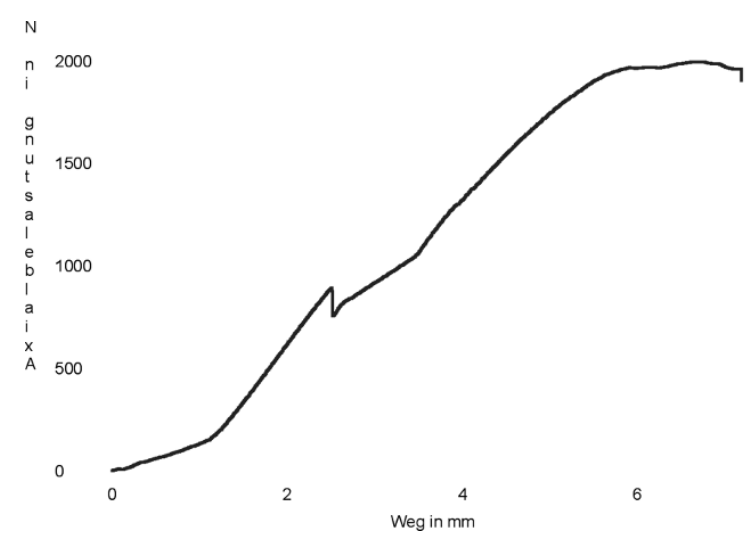

Diagram 2. curve with augmentation F max.: $2000.54 \mathrm{~N}$.

\section{DisCUSSION}

Fracture fixation with a hip screw has been studied clinically and biomechanically $[12,15,30]$. The treatment of unstable fractures classified as type A2 and A3 by the AO classification is a challenge. Loss of medial cortical support promotes a load increase for the implant. In 1973 Sarmiento described the need to reconstruct the medial cortex (calcar) as a supporting column to guarantee adequate fracture stability [51]. The high shear forces that follow the fracture of the medial cortex are a factor leading to varus forces. This forces act on the proximal femoral fragment and clinically promote the migration of the fixed hip screw through the spongious bone of the femoral head. This is the so called cut-out point.

The cut-out is the most important mechanism of failure in internal screw fixation. Davis et al. [16] examined the mechanism of mechanical failure in 230 internally fixed inter-trochanteric fractures of the femur. The results of their prospective study showed a mechanical failure in 16.5 percent of the cases; 76 percent of these were caused by the cut-out of the hip screw through the femoral head. Yoshemine et al. [64] examined the "slide“ characteristics of the hip screw depending on the fracture configuration. The primary reduction of the fragments as well as the quality of bone in 47 intertrochanteric fractures was analyzed.
All of them were stabilized with a Zimmer Compression Hip Screw (Zimmer USA, Warsaw, Indiana). The most frequent mode of failure was the cut-out of the hip screw. In all the cases the fractures were unstable in patients with osteoporosis.

Despite the efforts of the surgeons to achieve an anatomically correct or acceptable reduction of the fracture fragments the problem of the migration of the hip screw through the head was the most frequent mode of failure of the femoral screw fixation in unstable inter-trochanteric fractures of the femur $[5,16,23]$.

With regards to the incidence of fractures as well as to the risk of fracture the decreased bone density is often mentioned as a factor [14, 27, 43, 57] especially in patients of eighty years of age or older. The degree and extent of the osteoporosis is a major factor for the therapy. Multiple studies have verified higher rates of complications after osteosynthesis in osteoporotic bones $[1,16,45]$.

Our study included static in-vitro testing of isolated femoral neck screws in poly-urethanic cylinders acting as bone material. To simulate an osteoporotic bone a specific density of the bone replacement material was used. The mean density for the osteoporotic bone simulation was $0.192 \mathrm{~g} / \mathrm{cm}^{3}$ (force of compression $3.33 \mathrm{Mpa}$ ) as indicated by the manufacturer and correlated to a calculated age of 94 years [40]. Lenzner [37] reported bone densities between $0.190 \mathrm{~g} / \mathrm{cm}^{3}$ and $0.394 \mathrm{~g} / \mathrm{cm}^{3}$ (mean $0.272 \mathrm{~g} / \mathrm{cm}^{3}$ ) in his studies and correlated the bone density with the ability of the hip screw to maintain fracture stability in human femoral heads using QCT-assisted analyses.

The main focus is the cut-out point of the hip screws because the excessive migration in the proximal fragment was contained to the geometry of the proximal screw. The length of the screw as well as the lever rates occurring in the complete fixation system of the force carrier rest regardless of the standardized test design.

In the first group of tests without bone biopolymer augmentation the findings of the literature were confirmed.

The load at the initial cut-out point for the group with a density degree of $12\left(0.192 \mathrm{~g} / \mathrm{cm}^{3}\right)$ had a mean of 1431 Newton ( \pm 52 Newton) $[33,34]$. In the group with biopolymer augmentation the mean was 1987 Newton ( \pm 84 Newton). The results were analyzed using the two-tailed Student-T-Test and found to have a significant difference.

\section{CONCLUSION}

The migration of the hip-screws (cut-out) represents an associated patho-physiological and biomechanical problem since the introduction of this minimal-invasive technique for osteosynthesis. This becomes more important in the osteoporotic bone and often leads to serious clinical problems in the elderly population.

The bone density is a significant factor for the stability of the hip screw implant. The osteosynthesis with screws in material with low density increases the chance for cut-out. A biopolymer augmented hip screw could significantly improve the stability of the fixation. 
The use of augmentation with a fast hardening bone replacement material containing polymer-ceramic changes the point of failure under axial load in the osteoporotic bone model and could significantly improve the failure point. Our study results indicate, that a decrease of failure in terms of cut-out can be achieved with polymer augmentation of hip screws in osteoporotic bones.

\section{REFERENCES}

1. Alho A, Benterud JG, Solovieva S. Internally fixed femoral neck fractures; early prediction of failure in 203 elderly patients with displaced fractures. Acta Orthop Scand. 1999; 70(2): 141-144.

2. Baitner AC, Maurer SG, Hickey DG, Jazrawi LM, Kummer FJ, Jamal J, Goldman S, Koval KJ. Vertical shear fractures of the femoral neck. - A biomechanical study. Clin Orthop. Oct 1999; 367: 300-305

3. Bannister GC, Gibson AG, Ackroyd CE, Newman JH. The fixation and prognosis of trochanteric fractures; A randomised prospective controlled trial. Clinl Orthop. May 1990; 254: 242-246.

4. Bartucci EJ, Gonzalez MH, Cooperman DR, Freedberg H., Barmada R, Laros GS. The effect of adjunctive methylmethacrylate on failures of fixation and function in patients with intertrochanteric fractures and osteoporosis. J Bone Joint Surg. Sept 1985; 67-A(7): 1094-1107.

5. Baumgaertner MR, Curtin SL, Lindskog DM, Keggl JM. The value of the tip-apex distance in predicting failure of fixation of feritrochanteric fractures of the hip. J Bone Joint Surg. July 1995; 77-A(7): 1058-1064.

6. Bergmann G, Graichen F, Rohlmann A. Messung der Hüftgelenkbelastung bei zwei Patienten. Kongr. Biomedizinische Technik Band 36-Ergänzungsband (1991), pp 204-205.

7. Bergmann G, Rohlmann A, Graichen F. In vivo Messung der Hüftgelenkbelastung; 1. Teil Krankengymnastik. Z Orthop. 1989; 127: 627-679.

8. Boyd HB, Griffin LL. Classification and treatment of fractures. Arch Surg. 1949; 58: 853-866.

9. Brookes M, Revell WJ. Blood supply of bone; scientific aspects. Springer-Verlag Berlin, Heidelberg, New York (1998).

10. Chapman JR, Harrington RM, Lee KM, Anderson PA, Tencer AF, Kowalski D. Factors Affecting the Pullout Strength of Cancellous Bone Screws. J Biomech Eng. Aug 1996; 118(3): 391-398

11. Chapman JR, Harrington RM, Lee K, Forsyth E, Anderson PA. The influence of screw design and insertion technique on pullout strength of screws in porous materials. 38th Annual Meeting, Orthopaedic Research Society (February 1992).

12. Chinoy MA, Parker MJ. Fixed nail plates versus sliding hip systems for the treatment of trochanteric femoral fractures: A meta analysis of 14 studies. Injury. 1999; 30(3): 157-163.

13. Choueka J, Koval KJ, Kummer FJ, Crawford G, Zuckerman JD. Biomechanical comparison of the sliding hip screw and the dome plunger; Effects of material and fixation design. J Bone Joint Surg. March 1995; 77-B( 2): $277-$ 283.

14. Crofts RD, Boyce TM, Bloebaum RD. Aging changes in osteon mineralization in the human femoral neck. Bone. 1994; 15(2): 147-152

15. Davis TRC, Sher JL, Checketts RG, Porter BB. Intertrochanteric fractures of the femur: A prospective study comparing the use of the Küntscher-Y-nail and a sliding hip screw. Injury. 1988; 19(6): 421-426.

16. Davis TRC, Sher JL, Horsman A, Simpson M, Porter BB,
Checketts RG. Intertrochanteric femoral fractures; Mechanical failure after internal fixation. J. Bone Joint Surg. Jan 1990; 72-B(1): 26-31.

17. Debrunner HU. Studien zur Biomechanik des Hüftgelenks Int Z Orthop. 1975; 113: 377-388.

18. De Laet CE, Pols HA. Fractures in the elderly: Epidemiology and demography. Baill Best Pract Res Clin Endocr Metab. June 2000; 14(2): 171-179.

19. Elder S, Frankenburg E, Goulet J, Yetkinler D, Poser R, Goldstein S. Biomechanical evaluation of calcium phosphate cement-augmented. Fixation of unstable intertrochanteric fractures. J Orthop Trauma. Aug 2000; 14(6): 386-393.

20. Evans M. The treatment of trochanteric fractures of the femur. J Bone Joint Surg. May 1949; 31-B(2): 190-203.

21. Graichen F., Bergmann G. Four-channel telemetry system for in vivo measurement of hip joint forces. J Biomed Engineering. Sep 1991; 13: 370-374.

22. Gundle R, Gargan MF, Simpson AH. How to minimize failures of fixation of unstable intertrochanteric fractures. Injury. Nov 1995; 26(9): 611-614.

23. Hardy DCR, Descamps P-Y, Krallis P, Fabeck L, Smets P, Bertens C, Delince PE. Use of an intramedullary hip screw compared with a compression hip screw with a plate for intertrochanteric femoral fractures. J Bone Joint Surg. May 1998; 80-A(5): 618-630.

24. Hasegawa K, Yamamura S, Dohmae Y. Enhancing screw stability in osteosynthesis with hydroxyapatite granules. Acta Orthop Trauma Surg. 1998; 117: 175-176.

25. Haynes RC, Pöll RG, Miles AW, Weston RB. An experimental study of the failure modes of the gamma locking nail and $\mathrm{AO}$ dynamic hip screw under static loading: $\mathrm{A}$ cadaveric study. Med Eng Phys. 1997; 19(5): 446-453.

26. Haynes RC, Pöll RG, Miles AW, Weston RB. Failure of femoral head fixation : A cadaveric analysis of lag screw cut-out with the gamma nail and AO dynamic hip screw. Injury. 1997; 28(5-6): 337-341.

27. Hedström M, Svensson J, Dalén N. Biochemical bone markers and bone density in hip fracture patients. Acta Orthop Scand. 2000; 71(4): 409-413.

28. Jenny J-Y, Rapp E, Cordey J. Type of screw does not influence holding power in the femoral head. Acta Orthop Scand. 1999; 70(5): 435-438.

29. Jensen JS. Mechanical strength of sliding screw-plate hip implants: A biomechanical study of unstable trochanteric fractures. Acta Orthop Scand. 1980; 51: 625-632.

30. Jensen JS, Sonne-Holm S. Critical analysis of ender nailing in the treatment of trochanteric fractures. Acta Orthop Scand. 1980; 51: 817-825.

31. Jensen JS, Sonne-Holm S, Tøndevald E. Unstable trochanteric fractures; A comparative analysis of four methods of internal fixation. Acta Orthop Scand. 1980; 51: 949-962.

32. Jewett EL. One-piece angle nail for trochanteric fractures. J Bone Joint Surg. 1941; 23: 803-810.

33. Johansson T, Jacobsson S-A, Ivarsson I, Knutsson A, Wahlström O. Internal fixation versus total hip arthroplasty in the treatment of displaced femoral neck fractures: A prospective randomized study of 100 hips. Acta Orthop Scand. 2000; 71(6): 597-602

34. Karlsson MK, Obrant KJ, Nilsson BE, Johnell O. Bone mineral density assessed by quantitive ultrasound and dual energy X-ray absorptiometry. Acta Orthop Scand. 1998; 69(2): 189-193.

35. Kauffman JI, Simaon JA, Kummer FJ, Pearlman CJ, Zuckerman JD, Koval KJ. Internal fixation of femoral neck fractures with posterior comminution: A biomechanical study. J Orthop Trauma. 1999; 13(3): 155-159.

36. Kyle RF, Wright TM, Burstein AH. Biomechanical analysis of the sliding characteristics of compression hip screws. J Bone Joint Surg. Dec 1980; 62-A(8): 1308-1314. 
37. Lenzner A, Kaur I, Haviko T, Sögel V, Gapejeva J, Ereline J, Pääsuke M. Impaction bone-grafting increases the holding power of cancellous screws in the femoral head; A pull-out study in human cadaver hips. Acta Orthop Scand. 1999; 70(1): 25-28.

38. Loch DA, Kyle RF, Bechthold JE, Kane M, Anderson K, Sherman RE. Forces required to initiate sliding in secondgeneration intramedullary nails. J Bone Joint Surg. Nov 1998; 80-A(11): 1626-1631.

39. Madsen JE, Naess L, Aune AK, Alho A, Ekeland A, Strømsøe K. Dynamic hip screw with trochanteric stabilizing plate in the treatment of unstable proximal femoral fractures: A comparative study with the gamma nail and compression hip screw. J Orthop Trauma. 1998; 12(4): 241-248.

40. McCalden RW, Mcgeough JA, Court-Brown CM. Age-related changes in the compressive strength of cancellous bone. J Bone Joint Surg. March 1997; 79-A(3): 421-427.

41. Müller ME. Comprehensive classification of fractures pamphlet II for specialized trauma surgeons and researchers. Edition 1996

42. Müller ME, Allgöwer M, Schneider R, Willenegger H. Manual der Osteosynthese AO-Technik. Dritte erweiterte und völlig überarbeitete Auflage, Springer Verlag Berlin, Heidelberg, New York (1993).

43. Pande I, O’Neill TW, Pritchard C, Scott DL, Woolf AD. Bone mineral density, hip axis length and risk of hip fracture in men: Results from the Cornwall Hip Fracture Study. Osteoporos Int. 2000; 11(10): 866-870.

44. Park S-R, Kang J-S, Kim H-S, Lee W-H, Kim Y-H. Treatment of intertrochanteric fracture with the gamma AP locking nail or by a compression hip screw - A randomised trial. Int Orthopaedics. 1998; 22: 157-160.

45. Parker MJ, Blundell C. Choice of implant for internal fixation of femoral neck fractures: Meta-analysis of 25 randomised trials including 4.925 patients. Acta Orthop Scand. 1998; 69(2): 138-142.

46. Parker MJ, Walsh ME. Importance of sliding screw position in trochanteric fractures. Acta Orthop Scand. 1993; 64(1): 73-74.

47. Radford PJ, Needoff M, Webb JK. A prospective randomised comparison of the dynamic hip screw and the gamma locking nail. J Bone Joint Surg. 1993; 75-B(5): Sep 789-793.

48. Rantanen J, Aro HT. Intramedullary fixation of high subtrochanteric femoral fractures: A study comparing two implant designs, the gamma nail and the intramedullary hip screw. J Orthop Trauma. 1998; 12(4): 249-252.

49. Rha JD, Kim YH, Yoon SL, Park TS, Lee MH. Factors affecting sliding of the lag screw in intertrochanteric fractures. Int Orthop. 1993; 17: 320-324.

50. Sarmiento A, Williams EM. The unstable pertrochanteric fracture treatment with valgus osteotomy and I beam nail plate. J Bone Joint Surg. 1970; 52-A: 457.

51. Sarmiento A. Unstable intertrochanteric fractures of the femur. Clinl Orthop. May 1973; 92: 77-85.

52. Savvidis E, Stabrey H. Erste Werkstoffangepasste Anstrengungshypothese zur Berechnung der Vergleichsspannung an Humanen Femora. Biomed Tech. 1997; 42(10): 276-279.

53. Schipper IB, Streyerberg EW, Castelein RM, van Vugt AB. Reliability of the AO/ASIF classification for pertrochanteric femoral fractures. Acta Orthop Scand. Feb 2001; 72(1): 36-41.
54. Sim E, Schmiedmayer HB, Lugner P. Mechanical factors responsible for the obstruction of the gliding mechanism of a dynamic hip screw for stabilizing pertrochanteric femoral fractures. J Trauma. 2000; 49(6): 995-1001.

55. Simmermacher RK, Bosch AM, Van der Werken C. The AO/ASIF-proximal femur nail (PFN) : A new device for the treatment of unstable proximal femoral fractures. Injury. June 1999; 30(5): 327-332.

56. Singh M, Nagrath AR, Maini PS. Changes in trabecular pattern of the upper end of the femur as an index of osteoporosis. J Bone Joint Surg. April 1970; 52-A(2): 457467

57. Sjöstedt A, Zetterberg C, Hansson T, Hult E, Ekström L. Bone mineral content and fixation strength of femoral neck fractures: A cadaver study. Acta Orthop Scand. 65(2): 161-165.

58 Smith MD, Cody DD, Goldstein SA, Cooperman AM, Matthews LS, Flynn MJ. Proximal femoral bone density and its correlation to fracture load and hip-screw penetration load. Clin Orthop. Oct 1992; 283: 244-251.

59. Sochart DH. Poor results following internal fixation of displaced subcapital femoral fractures: Complacency in fracture reduction. Arch Orthop Trauma Surg. 1998; 117: 379-382.

60. Taeger G, Schmid C, Zettl R, Schweiberer L, Nast-Kolb D. Stable and unstable pertrochanteric femoral fractures. Differentiated indications for the dynamic hip screw. Unfallchirurgie. Sep 2000; 103(9): 741-748

61. Wagner R, Blattert TR, Weckbach A. Problemlösung der Extraartikullären, Koxalen Femurfraktur durch das „Gleitschrauben-Nagel-Prinzip“; Ergebnisse zweier verschiedener Systeme (Classic Nail und Gamma-Nagel). Unfallchirurgie. 1998; 101: 894-900.

62. Wang CJ, Brown CJ, Yettram AL, Procter P. Intramedullary femoral nails: One or two lag screws? A preliminary study. Med Eng Phys. 2000; 22(2): 613-624.

63. Wu CC, Shih CH, Lee MY, Tai CL. Biomechanical analysis of location of lag screw of a dynamic hip screw in treatment of unstable intertrochanteric fracture. J Trauma. 1996 Oct;41(4):699-702.

64. Yoshimine F, Latta LL, Milne EL. Sliding characteristics of compression hip screws in the intertrochanteric fracture: A clinical study. J Orthop Trauma. 1993; 7(4): 348353.

Received: November 1, 2009 / Accepted: January 15, 2010

Address for correspondence:

Dr. A. P. Schulz

Klinik für Chirurgie des Stütz- und Bewegungsapparates

Universitätsklinikum Schleswig-Holstein

Campus Lübeck

Ratzeburger Allee 160

23538 Lübeck

Germany

Tel. +49-451-5004730

Mob. +49-1791152967

E-mail: mail@apschulz.de 